\title{
Factor Affecting the Magnitude and the Direction of the Pressure Exerted on the Gravity Retaining Wall
}

\author{
Talal Masoud
}

\begin{abstract}
Gravity retaining wall are structures used to retain the soil by its weight the stability of such type of walls depend on the magnitude and direction of the horizontal forces exerted by soil . it found that there is many factors affect the value and the acting point of acting. Based on this, a study was conducted to investigate the effect of water table, external vertical loads, sloping of the backfill and the type of the backfill soil. It show that, the value of the horizontal soil pressure increase from $147 \mathrm{KN} / \mathrm{m}$ ' on dry soil to about $307 \mathrm{KN} / \mathrm{m}^{\prime}$ as the soil become saturated.also,effect of external loads are studied, and show its increase the total horizontal forces of the soil pressure. Sloping the backfill soil behind the retaining wall also great effect on the earth pressure. The type of the backfill soil behind the retaining wall also investigated and found its effect of the earth forces.
\end{abstract}

Keywords - Gravity mass retaining wall, Earth pressure, Backfill, Retaining wall, Drainage system, Vertical loads, Internal friction.

\section{INTRODUCTION}

Retaining structures in general used to retain soil and keep the earth in the same position under any forces exerted by the soil. The problems associated retaining wall is a function of the value and point of acting on the earth pressure, analysis of all forces acting on the

retaining wall required to understand the behavior of the wall and the factor affecting these forces. In this research of internal friction of the soil $\varnothing$, effect of water , effect of external loads and effect of sloping of the soil were studier $[1,2,3,4,5,6$.$] ,$

\section{EARTH PRESSURE}

The mass of the soil founded at a depth $\mathrm{Z}$ from the ground surface of the ground was subjected two types of forces , vertical and horizontal forces as shown below on fig 1 .

Revised Manuscript Received on June 30, 2020.

* Correspondence Author

Dr. Talal Masoud*, Civil Engineering Department, College of Engineering, Jerash University, Jerash, Jordan Email: t.masoud@jpu.edu.jo

(c) The Authors. Published by Blue Eyes Intelligence Engineering and Sciences Publication (BEIESP). This is an open access article under the CC BY-NC-ND license (http://creativecommons.org/licenses/by-nc-nd/4.0/)

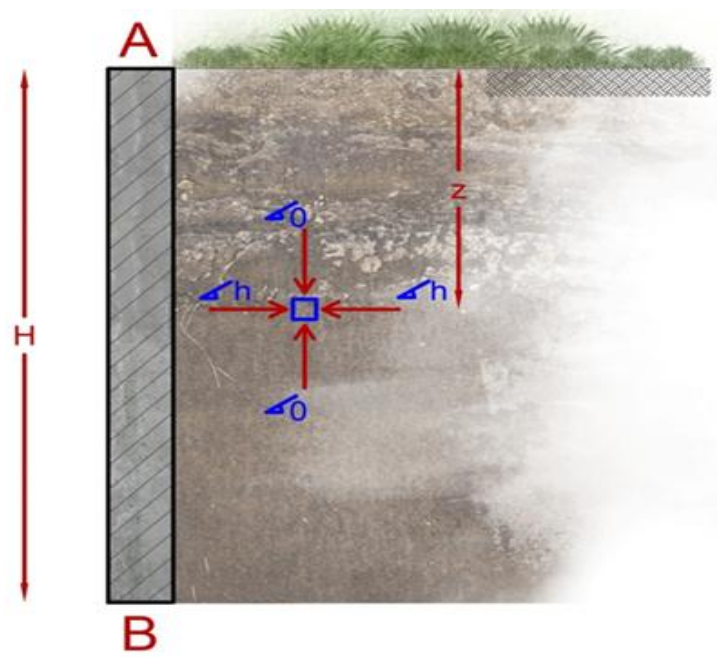

Figure 1: show The soil mass found at a depth $\mathrm{Z}$ from the surface of the ground is subjected to a vertical and horizontal forces.

If the wall moving away from the backfill , the soil mass expands. And forces is called active earth forces( $\sigma a)$ and

$\sigma_{a}=\sigma_{h}=k_{a} \sigma_{v}$ where

$$
\sigma_{v}=\sigma_{z}
$$

And

$$
k_{a}=\frac{1-\sin \emptyset}{1+\sin \emptyset}
$$

$\mathrm{Ka}=$ is the coefficient at active earth forces.

To understand the factors effecting the magnitude and the direction of active earth forces, various case and different type of backfill were investigated as show in the examples below $[7,8,9,10,11]$.

Case I

Suppose that a retaining wall $7 \mathrm{~m}$ high retain a backfill with $\varnothing=30^{\circ}$ and $\gamma=18 \mathrm{KN} / \mathrm{m}^{3}$

and the spoil material behind the retaining wall has a horizontal of surface level with the top of the wall then , the total horizontal forces exerted by the soil behind the wall is given by:

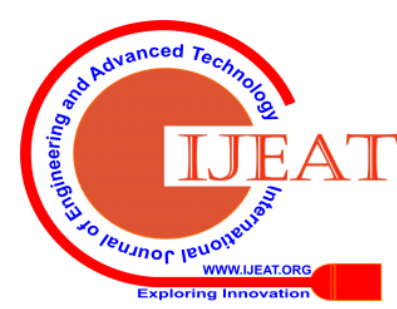




$$
P_{a}=\left(\frac{1}{2}\right)(\gamma)\left(k_{a}\right)(H)^{2}
$$

where

$\mathrm{H}=$ the total high of the wall

$\mathrm{Pa}=147 \mathrm{KN} / \mathrm{m}^{\prime}$, acting at distance equal to $\mathrm{H} / 3=2.33 \mathrm{~m}$

From the base of the wall as show on figure 2

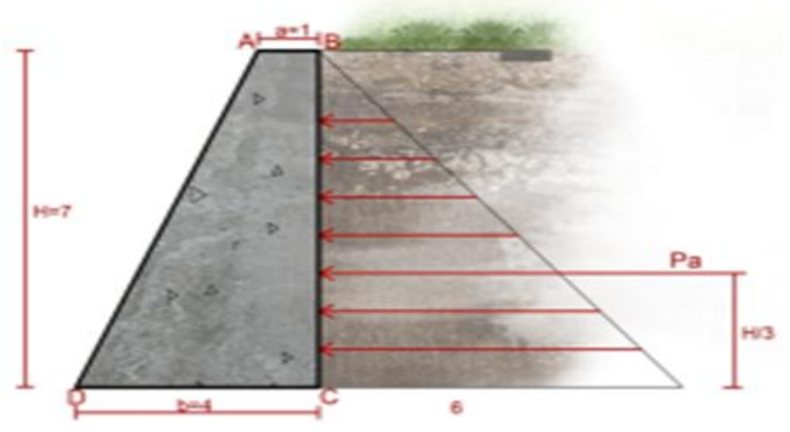

Figure 2: show the gravity retaining wall and loads. Case II

As the same as case I but in this case the wall retains a moist soil (that is the water table at the top of surface of the ground) In this case , the horizontal earth forces acting on the wall is due to the soil and due to the water as shown on figure 3

$$
k_{a}=\frac{1-\sin \emptyset}{1+\sin \emptyset}=\frac{1}{3}
$$

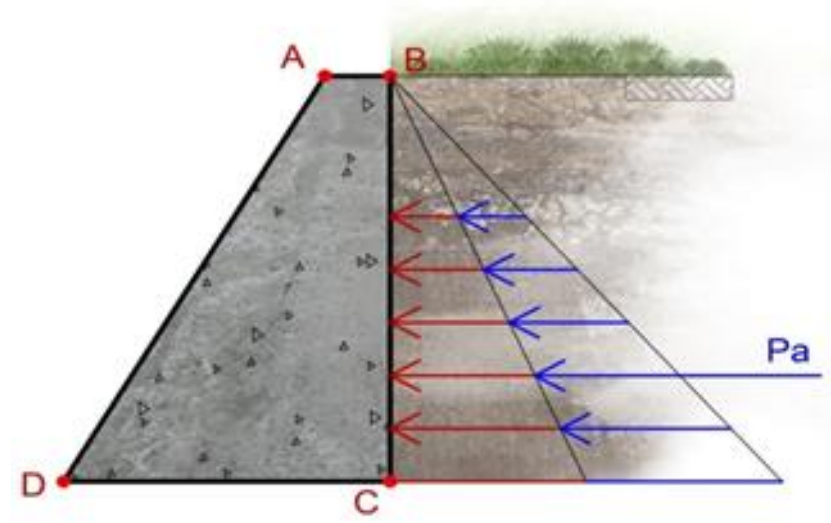

Figure3: show the horizontal earth forces acting on the wall is due to the soil and due to the water.

$\bar{\gamma}=$ is the affection weight

Where

$\gamma_{\mathrm{w}}=$ the unit weight of the water $=9.81 \mathrm{KN} / \mathrm{m}^{3}$

$\bar{\gamma}=18-9.81=8.19$

$$
\begin{aligned}
& \sigma_{1}=(8.91)\left(\frac{1}{3}\right)(7)=19.11 \mathrm{KN} / \mathrm{m}^{3} \\
& \sigma_{2}=\gamma_{W} H=(9.81)(7)=68.67 \mathrm{KN} / \mathrm{m}^{3} \\
& P_{a}=\frac{1}{2}\left(\sigma_{1}+\sigma_{2}\right)(H) \\
& P_{a}=\frac{1}{2}(19.11+68.67)(7)=307.23 \mathrm{KN} / \mathrm{m}^{\prime}
\end{aligned}
$$

Acting at $2.33 \mathrm{~m}$ from the base.

\section{Case III}

$$
\sigma_{1}=k_{a} \bar{\gamma} H
$$

As the same of case I, but the soil surface was subjected to external vertical load of $\mathrm{Pu}=45 \mathrm{KN} / \mathrm{m}^{2}$ as shown below in figure 4

$$
\bar{\gamma}=\gamma_{s}-\gamma_{w}
$$

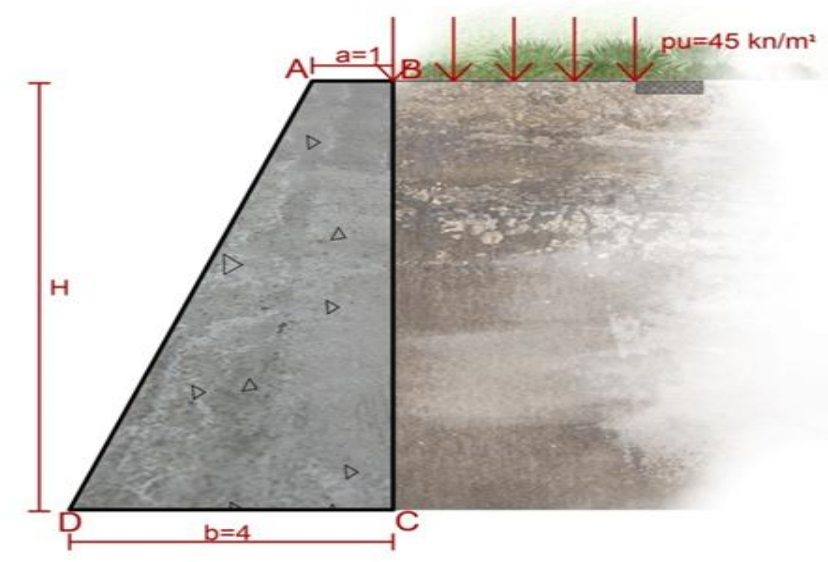

Figure 4: shows the gravity retaining wall and the external loads.

In this case the total horizontal forces is due to the external loads and due to the soil as shown in figure 5

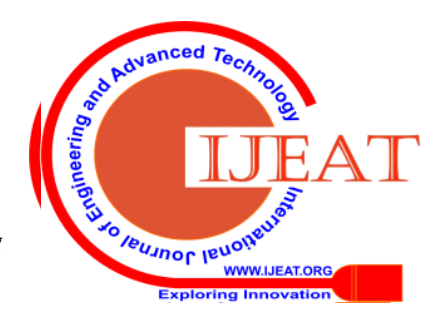




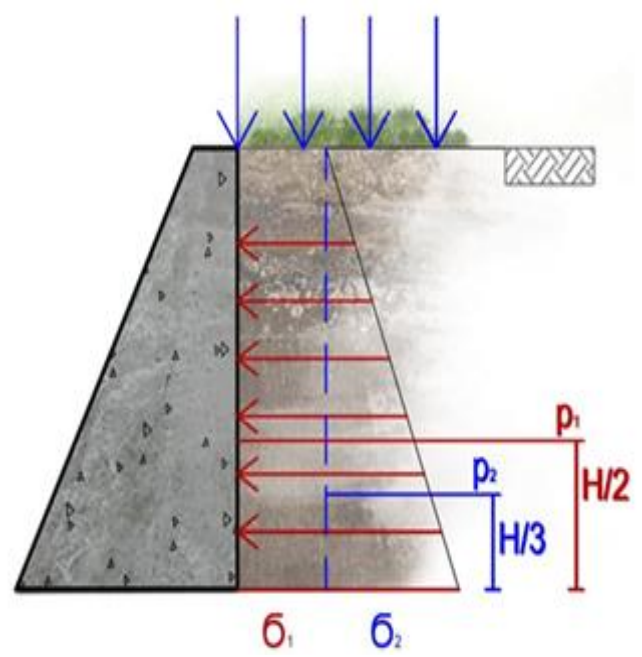

Figure 5: shows the total horizontal forces due to the external loads and due to the soil.

$\sigma_{1}=k_{a} Q=\left(\frac{1}{3}\right)(45)=15 \mathrm{KN} / \mathrm{m}^{2}$

$\sigma_{2}=k_{a} \gamma H=\left(\frac{1}{3}\right)(18)(7) 42 K N / m^{2}$

$P_{1}=\left(\sigma_{1}\right)(H)=15(7)=105 \mathrm{KN} / \dot{m}$

at $\frac{H}{2}=\frac{7}{2}=3.5$ M FROM BASE

$P_{2}=\left(\frac{1}{2}\right)(42)(7)=147 K N / m$

at $\frac{H}{3}=\frac{7}{3}=2.33$

Total horizontal forces (P)

$P=P_{1}+P_{2}=105+147=252 \mathrm{KN} / \dot{m}$

\section{Case IV}

The same as case I but the backfill has a slope of $25^{\circ}$ with the horizontal as shown As shown on figure 6.

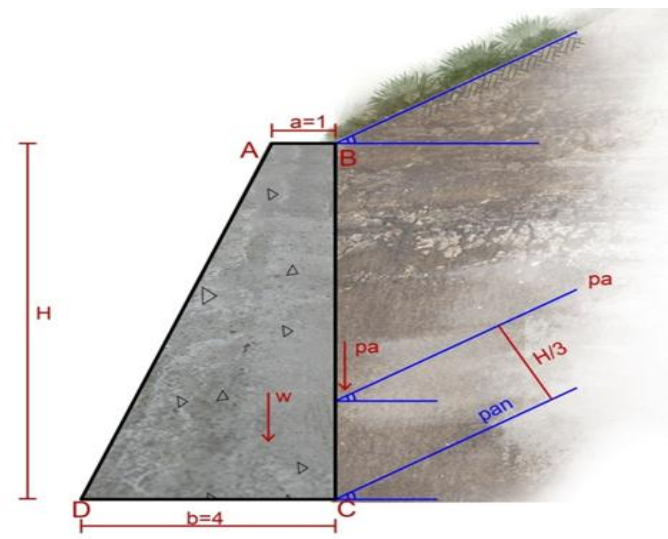

Figure 6: show forces and direction of the force with sloping backfill.
$\mathrm{K}_{\mathrm{a}}=$ in this case, the active earth forces coefficient given by

$$
k_{a}=\cos \alpha \frac{\cos \alpha-\sqrt{\cos \alpha^{2}-\cos \emptyset^{2}}}{\cos \alpha+\sqrt{\cos \alpha^{2}-\cos \emptyset^{2}}}
$$

The total earth forces $\mathrm{P}_{\mathrm{a}}$ is

$$
\begin{aligned}
& P_{a}=\left(\frac{1}{2}\right)\left(\gamma_{s}\right)(H)^{2} k_{a} \\
& =\left(\frac{1}{2}\right)(18)(7)^{2}(0.4936) \\
& P_{a}=217.68 \mathrm{KN} / m^{\prime}
\end{aligned}
$$

\section{Case V}

The same case I , but the type of the type of the soil behind the wall is change with different of internal friction angle, that is $(\varnothing)=20^{\circ}$

$$
\begin{aligned}
& k_{a}=\frac{1-\sin \emptyset}{1+\sin \emptyset}=0.4903 \text { and } \\
& P_{a}=\left(\frac{1}{2}\right)\left(k_{a}\right)(\gamma)(H)^{2}=216.22 \mathrm{KN} / m^{\prime}
\end{aligned}
$$

$$
k_{a}=0.4936
$$

\section{DISCUSSION}

This study shows the factors affected the magnitude and the direction of the horizontal soil forces external on the retaining wall. In the case I the backfill is dry and the magnitude of lateral earth forces is $147 \mathrm{KN} / \mathrm{m}^{\prime}$ and case II the same of case I but the soil is moist soil, in this case the lateral earth forces become $307.23 \mathbf{K N} / \mathbf{m}^{\prime}$ as an effect of the water.

Case III show the direct effect of external forces on the magnitude and direction of the horizontal soil forces, it show that the lateral earth pressure increase up to $252 \mathrm{KN} / \mathbf{m}^{\prime}$

As the top soil subjected to external vertical loads .[[12,13,14,15,16,17].

Effect of the slope of the backfill is shown in cease IV. It show that as the backfill not horizontal (has inclination with the horizontal) then the total horizontal earth forces increase up to $\mathrm{Pa}=217.68 \mathrm{KN} / \mathbf{m}^{\prime}$

Case $\mathrm{V}$ show the effect of angle of internal friction ( $\varnothing$ ) it show as the $(\varnothing)$ decrease from $30^{\circ}$ degree to $20^{\circ}$ degree The total earth forces increase to $216 \mathbf{K N} / \mathbf{m}^{\prime}$.

\section{CONCLUSION}

Based on the calculations of the lateral soil forces acting on the retaining wall at different cases the following conclusions are drawn.

1. This study shows the effect of the water on the soil behind the retaining wall on the magnitude of earth forces and the important of drainage system.

Published By:

Blue Eyes Intelligence Engineering \& Sciences Publication 
2. The effect of vertical loads behind the retaining wall also investigated and show as the external vertical loads increase, the magnitude of the lateral earth forces also increase.

3. On the other hand, as the backfill is not horizontal, has a slopping with horizontal, the magnitude and the direction of the lateral earth forces also increase.

4. Angle of internal friction of the backfill soil has a large effect, it show that as the $\varnothing$ decrease, the magnitude of the lateral earth forces increase.

\section{REFERENCES}

1. Cascone, E. Model tests and modelling of the dynamic behaviour of retaining walls, Ph.D. Thesis, University of Catania, 1996 (in Italian).

2. Elman, M. T. and Terry, C. F. (1988). "Retaining Walls with Sloped Heel," Journal of Geotechnical Engineering, American Society of Civil Engineers, Vol. 114, No. GT10, pp. 11941199.

3. Bell, J. R., Stilley, A. N., and Vandre, B. (1975). "Fabric Retaining Earth Walls," Proceedings, Thirteenth Engineering Geology and Soils Engineering Symposium, Moscow, ID.

4. Masoud, T., Alsharie, H., Abu Salem, Z., Yahia, Y., \& Suliman, M. (2018). Optimization of Shape Design for Gravity Retaining Walls, IJISME, Vol. 5, No. 8.

5. Nagre, S., Shinde, R., Ladkat, S., and Mahisare, K. (2017). "CASE STUDY OF RETAINING WALL," 7th International Conference on Recent Trends in Engineering, Science \& Management, India.

6. Okabe, S. (1926). "General Theory of Earth Pressure," Journal of the Japanese Society of Civil Engineers, Tokyo, Vol. 12, No. 1.

7. Richards, R.R. Jr. \& Elms, D.G. Seismic behaviour of gravity retaining walls, Journal of the Geotechnical Engineering Division, 1979, 105, No. 4, pp. 449-464.

8. Shukla, S. K., Gupta, S. K., and Sivakugan, N. (2009). “Active Earth Pressure on Retaining Wall for $c-\varnothing$ Soil Backfill Under Seismic Loading Condition," Journal of Geotechnical and Geoenvironmental Engineering, ASCE, Vol. 135, No. 5, 690-696.

9. Whitman, R.V. \& Liao, S. Seismic design of gravity retaining walls. Proceedings of the 8th World Conference on Earthquake Engineering. San Francisco, 1984, Vol. III, pp. 533-540.

10. Zarrabi-Kashani, K. Sliding of gravity retaining walls during earthquake considering vertical acceleration and changing inclination of failure surface, M.S. Thesis, Dept. of Civ. Eng., MIT, Cambridge, USA, 1979.

11. Subba Rao, K. S. and Choudhury, D. (2005). "Seismic Passive Earth Pressures in Soil," Journal of

12. Geotechnical and Geoenvironmental Engineering, ASCE, Vol. 131, No. 1, pp. 131-135.

13. Shields, D. H. and Tolunay, A. Z. (1973). "Passive Pressure Coefficients by Method of Slices," Journal of the Soil Mechanics and Foundations Division, ASCE, Vol. 99, No. SM12, pp. 10431053.

14. Laba, J. T. and Kennedy, J. B. (1986). "Reinforced Earth Retaining Wall Analysis and Design," Canadian Geotechnical Journal, Vol. 23, No. 3, pp. 317-326.

15. Crespellani, T., Madiai, C. \& Vannucchi, G. Earthquake destructiveness potential factor and permanent displacements of gravity retaining walls, Proc. Analysis and Design of Retaining Structures Against Earthquakes, Washington, ASCE Geo-Special Publ. No. 60, 1996, pp. 124-133.

16. Chouksey, S. K., \& Fale, A. (2017). Reliability Analysis of Counterfort Retaining Wall. International Journal of Civil Engineering and Technology, 8(7).

17. Cascone, E. Model tests and modelling of the dynamic behaviour of retaining walls, Ph.D. Thesis, University of Catania, 1996 (in Italian).

18. Cakir, T., Livaoglu, R., \& Dogangün, A. (2008). Effects of different backfill soil types on dynamic behavior of rectangular tank wall considering backfill-wall-fluid interaction. In The 14th World Conference on Earthquake Engineering (14WCEE) (pp. 014-0162).

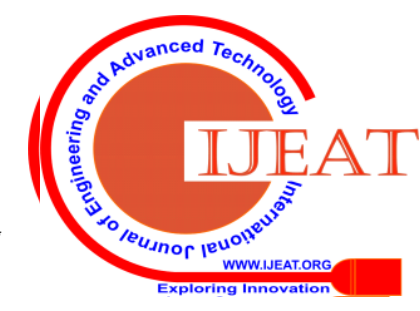

